\title{
ALTERAÇÕES INTRODUZIDAS PELA LEI N 12.529/2011 QUANTO AO MOMENTO PARA ANÁLISE DOS ATOS DE CONCENTRAÇÃO DE EMPRESA.
}

\author{
Mayara Souza de Oliveira, João Paulo A. Vasconcelos \\ Universidade do Oeste Paulista - UNOESTE. Curso de Direito, Presidente Prudente - SP.
}

\section{RESUMO}

O presente artigo visa apresentar algumas alterações trazidas pela lei antitruste de 2011 ao sistema de análise dos atos de concentração de empresa. Na vigência da lei anterior, os agentes econômicos participantes escolhiam entre a submissão prévia ou a posteriori do ato ao Conselho Administrativo de Defesa Econômica - CADE. Com a promulgação da nova Lei Antitruste, a análise passou a ser necessariamente prévia e, com efeito, a operação societária ou empresarial só poderá ser concretizada após decisão positiva do CADE, sob pena de aplicação de multa. A novel regulação coloca em debate doutrinário os prós e contras advindos com a modificação, os quais serão analisados no decorrer deste artigo.

Palavras-chave: Direito empresarial. CADE. Lei antitruste.

\section{AMENDMENTS BY LAW N¹2.529 / 2011 REGARDING THE TIME FOR ANALYSIS OF ACTS OF CONCENTRATION OF COMPANY.}

\begin{abstract}
This article presents some changes introduced by the 2011 law antitrust analysis of mergers enterprise system. Under the previous law, participants chose between economic agents prior to submission or subsequent act of the Administrative Council for Economic Defense - CADE. With the promulgation of the new Antitrust Law, the analysis has to be necessarily previous and indeed the corporate or business operation can only be achieved after positive decision by CADE, under penalty of a fine. A novel regulation puts in doctrinal debate the pros and cons coming with the change, which will be discussed throughout this article.
\end{abstract}

Keywords: Business Law. CADE. Antitrust Law. 


\section{INTRODUÇÃO E OBJETIVO}

A Lei Antitruste de 2011 alterou o momento de apreciação pelo Conselho Administrativo de Defesa Econômica - CADE dos atos de concentração de empresa que, até então, poderiam ser realizados antes, ou após a concretização da concentração empresarial, no prazo máximo de quinze dias úteis. Após as referidas alterações os atos de concentração, seja por meio de fusão, incorporação, aquisição, joint ventures, consórcios ou contratos associativos e etc., devem ser analisados previamente e, somente na hipótese de aprovação pelo CADE, poderão ser consumados pelos interessados. (SALLES, 2012).

A partir das mudanças implementadas, surgiram críticas ao novo modelo, expostas comparativamente ao sistema anterior, que se referem à existência de divergências acerca do momento da aprovação dos atos de concentração de empresa e quanto aos prazos previstos para realização da análise estatal, se prejudiciais ou não às partes envolvidas.

O escopo deste artigo é abordar as alterações acarretadas pela reforma na legislação antitruste, em razão da Lei $n^{\circ} 12.529 / 2011$, que ocasionou mudanças significativas na forma de submissão dos atos de concentração ao crivo do CADE.

\section{METODOLOGIA}

$\mathrm{O}$ artigo foi norteado por pesquisas bibliográficas, leituras, fichamentos, bem como por leis, decretos, resoluções e artigos eletrônicos. Os dados foram analisados com emprego do método hipotético-dedutivo, ou seja, partindo do geral para o particular e as informações coletadas analisadas e confrontadas de forma dialética.

\section{DISCUSSÃO}

A liberdade econômica foi elevada a nível constitucional pela Constituição de 1934 e, atualmente, o artigo 170, caput e inciso IV, da constituição vigente, apresentam como princípio da atividade econômica, a livre iniciativa e a livre concorrência. (FORGIONI, 2008). Não obstante a previsão constitucional, a livre concorrência é assegurada e regulada pela Lei Federal $n^{\circ} 12.529$ de 30 de novembro de 2011, a atual Lei Antitruste, que dispõe sobre as infrações contra ordem econômica, bem como, sobre a repressão e combate os atos nocivos à livre concorrência perpetrados pelos agentes econômicos (BRASIL, 2011).

Em seu artigo 36, caput, e incisos I a IV, a lei citada estabelece que constituem infração da ordem econômica, independentemente de culpa, os atos que tenham por objeto limitar, falsear ou de qualquer forma prejudicar a livre concorrência ou a livre iniciativa, dominar mercado 
relevante de bens e serviços, aumentar arbitrariamente os lucros e, por fim, exercer de forma abusiva posição dominante.

Para os efeitos deste estudo, considera-se ato de concentração empresarial o acordo realizado entre duas ou mais empresas que anteriormente exerciam atividade econômica de maneira independente. (DUTRA, 1997).

A fiscalização dos agentes econômicos pelos órgãos antitrustes se faz necessária, em razão da possibilidade de causação de graves impactos decorrentes de condutas anticoncorrenciais, tanto para o mercado, quanto para a sociedade como um todo, pois, podem levar à dominação de mercado e elevação dos preços de forma arbitrária e, consequentemente, gerar um aumento ilícito nos lucros dos agentes econômicos participantes dessa operação, em detrimento do interesse coletivo e do mercado.

Segundo Pagotto, Maggi e Grecco (2012, p.10).

O controle de concentrações é um elemento vital da política antitruste e seu funcionamento é crucial para a manutenção da concorrência. Não basta reprimir as condutas que violam a concorrência, é preciso evitar as operações que ameacem a concorrência.

A Lei antitruste atual revogou a Lei $n^{\circ} 8.884 / 1994$ que, até então, regulava a prevenção e repressão das infrações contra a ordem econômica (BRASIL, 2011).

Uma das mudanças trazida pela nova lei diz respeito à forma de submissão dos atos de concentração empresarial à apreciação do CADE e aos prazos previstos para análise das respectivas operações.

O artigo 54 da Lei $n^{\circ} 8.884 / 94$ e seu $\S 4^{\circ}$ previa que:

Os atos, sob qualquer forma manifestados, que possam limitar ou de qualquer forma prejudicar a livre concorrência, ou resultar na dominação de mercados relevantes de bens ou serviços, deverão ser submetidos à apreciação do CADE. $[\ldots]$

$\S 4$ ㅇ Os atos de que trata o caput deverão ser apresentados para exame, previamente ou no prazo máximo de quinze dias úteis de sua realização, mediante encaminhamento da respectiva documentação em três vias à SDE, que imediatamente enviará uma via ao CADE e outra à SPE. (BRASIL, Congresso Nacional, 1994. s.p.).

Dessa forma, na vigência da lei anterior, os atos de concentração podiam (e não deveriam) ser submetidos à apreciação do CADE previamente, ou então posteriormente, no prazo máximo de 15 dias, a contar da realização do acordo. Assim, ficava a critério dos agentes econômicos o momento da apresentação, desde que observado o prazo máximo previsto na lei em vigência. 
Apesar da existência da possibilidade de apresentação prévia do ato de concentração, Fernando de Magalhães Furlan (apud MONTEIRO, 2012, p. 19), aludindo ao sistema anterior, asseverava que "de fato, a possibilidade de notificação prévia já existe, porém é utilizada de modo absolutamente esparso, o que demonstra a necessidade de uma reformulação no sistema para que seja utilizada".

A lei $8.884 / 94$, também previa no $\S 7^{\circ}$, do artigo 54 , a aprovação tácita do ato de concentração na hipótese de decurso do prazo máximo de 120 dias previsto no $\S 6^{\circ}$ do aludido artigo.

Com o início da vigência da nova Lei Antitruste, que ocorreu em 29 de maio de 2012, o sistema de controle dos atos de concentração modificou-se substancialmente. (AGU, 2012). A análise que era perpetrada antes ou após a realização do ato de concentração, passou a ser, obrigatoriamente, prévia, sob pena de cometer gun-jumping, que consiste na prática de atos de concentração sem a análise e autorização prévia da autoridade antitruste. (MONTEIRO, 2012).

As modificações introduzidas pela Lei Antitruste vigente no controle de concentrações, não se limitou apenas ao critério temporal, mas alterou também os prazos para análise dos atos de concentração, que na vigência da lei anterior era de no máximo 120 (cento e vinte) dias.

Sob a égide da Lei $12.529 / 2011$, os prazos tornaram-se mais longos e com possibilidade de prorrogação, na forma do artigo $88, \S \S 2^{\circ}$ e $9^{\circ}$, que estipula o prazo máximo de 240 (duzentos e quarenta) dias para análise da concentração, prevendo, ainda, a possibilidade de prorrogação por 60 (sessenta) dias, na hipótese de requisição das partes, ou 90 (noventa) dias, quando houver decisão fundamentada do tribunal.

Art. 88. [...]

§ 20 O controle dos atos de concentração de que trata o caput deste artigo será prévio e realizado em, no máximo, 240 (duzentos e quarenta) dias, a contar do protocolo de petição ou de sua emenda.

$[\ldots]$

§ 9ㅇ O prazo mencionado no § 2 ㅇ deste artigo somente poderá ser dilatado:

1 - por até 60 (sessenta) dias, improrrogáveis, mediante requisição das partes envolvidas na operação; ou

II - por até 90 (noventa) dias, mediante decisão fundamentada do Tribunal, em que sejam especificados as razões para a extensão, o prazo da prorrogação, que será não renovável, e as providências cuja realização seja necessária para o julgamento do processo. (BRASIL, Congresso Nacional, 2011, s.p.).

Segundo Luiz Eduardo Salles (2012), uma questão bastante interessante que se levanta com a redação do aludido artigo é se as prorrogações por ele previstas são cumuláveis ou não, haja vista que a partícula "ou" leva a entender que poderá ser aplicada a prorrogação de 60 
(sessenta) dias ou de 90 (noventa) dias, não podendo ser concedida as duas prorrogações em um único processo de análise de concentração.

Aduz, ainda, o ilustre autor que o parágrafo $9^{\circ}$ do artigo 88 , dá margem a três possíveis interpretações, dessa forma, se a partícula "ou" for interpretada de forma absolutamente exclusiva, a prorrogação concedida ao Tribunal impediria a possibilidade de prorrogação por requisição das partes e vice-versa. No entanto, se a partícula "ou" for interpretada de forma extensiva, sendo empregada no sentido de "e", tanto a parte, quanto o Tribunal poderão requerer a prorrogação do prazo. Finalmente, se a partícula "ou" for interpretada de forma parcialmente inclusiva, ambos poderão requerer a prorrogação do prazo, entretanto, esse prazo não poderá exceder a 90 (noventa) dias quando somados, pois esse seria o prazo máximo de prorrogação permitido. Finaliza o autor:

Em suma, tendo em vista possível dissonância de perspectivas entre autoridade e partes e à luz da possibilidade de interpretação da partícula "ou" de forma inclusiva (no sentido de "e"), entendemos que a interpretação que permite a cumulação entre as extensões é possível e seria a mais apropriada. (SALLES, 2012, p.7).

Dessa forma, segundo o entendimento do autor citado acima, o prazo máximo para análise dos atos de concentração pelo CADE, na forma da nova lei, poderá ser de até 390 (trezentos e noventa) dias.

Além do momento para análise da concentração e a mudança nos prazos, a Lei 12.529/2011, não prevê a possibilidade de aprovação tácita na hipótese de decurso do prazo, diferentemente da lei por ela revogada.

O artigo 64 do projeto da atual lei antitruste previa a possibilidade de aprovação tácita em razão do decurso do prazo, mas recebeu veto presidencial. (SALLES, 2012). Todavia, a possibilidade de aprovação tácita não foi absolutamente afastada, porquanto, o Regimento Interno do Conselho Administrativo de Defesa Econômica - RICADE (p. 44, 2013) estabelece em seu artigo 133 que "O descumprimento dos prazos previstos nos §§ 2으 e 9을 do art. 88 da Lei n으 12.529, de 2011, implica a aprovação tácita do ato de concentração econômica".

Ambas as formas de submissão dos atos de concentração ao crivo do CADE sofreram críticas.

Ao analisar a antiga lei antitruste, Maria Cecília Andrade, Fernando Passos e Ubiratan Mattos (apud CASTRO, s.d, p.1) asseverava que:

Na notificação a posteriori, o que se privilegia é a liberdade de iniciativa, a presunção de legalidade do ato e a boa-fé das partes, valores fundamentais em 
um Estado de Direito. Na notificação prévia é o contrário. Restringe-se a liberdade de iniciativa, presume-se que o ato seja ilegal e, por isso mesmo, há que se pedir a bênção do Príncipe para realizá-lo.

No entanto, sob a égide da lei anterior, quando os atos eram submetidos posteriormente à análise, o acordo já realizado não trazia segurança jurídica às partes integrantes do ato de concentração, porquanto, não obstante a efetivação do referido ato, a sua eficácia ficava subordinada a decisão do CADE para se aperfeiçoar, ficando subordinado a uma condição suspensiva, qual seja a aprovação pelo órgão antitruste, caso contrário, a concentração empresarial deveria ser desfeita na forma prevista na lei 8.884/1994. (AGU, 2012).

$\mathrm{O}$ ato de concentração "Nestlé-Garoto" foi realizado na vigência da antiga lei antitruste, sendo submetido à apreciação pelo CADE após a concretização do negócio. No entanto, após 411 (quatrocentos e onze) dias, o órgão antitruste entendeu que a concentração em análise era prejudicial ao mercado, e determinou que a Nestlé vendesse a marca adquirida para outra empresa concorrente, detentora de menos de $20 \%$ de participação no mercado relevante. As empresas participantes do ato de concentração contestaram a decisão do CADE perante o Poder Judiciário, que proferiu decisão favorável à concentração, reconhecendo a aprovação tácita em decorrência do decurso do prazo. $\mathrm{O}$ ato de concentração ora citado foi submetido à apreciação em março de 2002 e, desde então, não há uma decisão definitiva do Judiciário. Esse é um exemplo de que o sistema de análise posterior traz insegurança aos agentes econômicos participantes do ato, haja vista a possibilidade de sua não aprovação. (CARRIL, 2012).

Haveria, assim, uma vantagem da lei nova ante o sistema anterior, já que a sujeição é sempre prévia.

No entanto, a crítica dirigida ao novo sistema implantado concerne ao prazo de duração do processo de análise, à morosidade para a manifestação decisiva do Estado, que, dependendo da complexidade do caso, poderá correr por longos 390 (trezentos e noventa) dias, isto é, a resposta da autoridade antitruste pode levar mais de um ano, revelando-se um potencial mecanismo de inviabilização do ato submetido à apreciação e, com efeito, da própria preservação da empresa. Ora, na hipótese de uma das empresas participantes da operação de concentração encontrar-se acometida de crise financeira e lançar mão de operação societária para viabilizar a sua continuidade no mercado, a espera obrigatória da autorização do CADE pode trazer-lhe prejuízos, senão inviabilizar a sua recuperação. No mesmo sentido: SALLES, 2012, p. 3. 


\section{CONCLUSÃO}

Ao longo desse estudo, foram abordadas as principais alterações trazidas pela nova Lei Antitruste à análise dos atos de concentração empresarial, e as críticas direcionadas tanto ao antigo sistema de aprovação adotado pela lei anterior, quanto ao novo sistema implantado pela Lei $12.529 / 2011$.

A despeito das críticas direcionadas ao novo sistema de análise dos atos de concentração, a referida mudança trouxe segurança jurídica aos atos de concentração que somente poderão ser realizados após a decisão positiva do Conselho Administrativo de Defesa Econômica - CADE, dessa forma, evitando-se, por exemplo, o desperdício de recursos financeiros, que seriam empregados apenas na hipótese de aprovação.

Conquanto sérios os argumentos segundo os quais o sistema de análise prévia pode inviabilizar a realização dos atos de concentração, em razão do maior prazo previsto pela Lei 12.529/2011, deve-se observar que o Regimento Interno do Conselho Administrativo de Defesa Econômica - RICADE (2013) estabelece, em seu artigo 115, a possibilidade de autorização liminar para realização do ato de concentração, desde que comprovado a existência cumulativa de ausência de perigo de dano irreparável a concorrência, reversibilidade da medida requerida, e risco de grande prejuízo financeiro irreversível para empresa adquirida, na hipótese de não autorização liminar e precária para realização do ato. Admite-se, assim, mediante comprovação da necessidade da operação, a "concretização" do ato antes mesmo da aprovação pelo CADE.

\section{REFERÊNCIAS}

BRASIL. Conselho Administrativo de Defesa Econômica (CADE). Regimento interno do conselho administrativo de defesa econômica - RICADE. Consolido em 18 de mar. 2013. Disponível em: < http://www.cade.gov.br/upload/RICADE\%20atual..pdf> Acesso em: 08 ago. 2014.

BRASIL. Congresso Nacional. Lei $n^{\circ} 8.884$ de 11 de junho de 1994. Transforma o Conselho Administrativo de Defesa Econômica (CADE) em Autarquia, dispõe sobre a prevenção e a repressão às infrações contra a ordem econômica e dá outras providências. Diário Oficial, 13 de jun. de 1994. Disponível em: <https://www.planalto.gov.br/ccivil_03/leis//8884.htm>. Acesso em: 09 ago. 2014.

BRASIL. Congresso Nacional. Lei $n^{\circ} 12.529$ de 30 de novembro 2011. Estrutura o Sistema Brasileiro de Defesa da Concorrência; dispõe sobre a prevenção e repressão às infrações contra a ordem econômica; altera a Lei nำ 8.137, de 27 de dezembro de 1990, o Decreto-Lei $\mathrm{n}^{\circ}$ 3.689, de 3 de outubro de 1941 - Código de Processo Penal, e a Lei $n^{\circ}$ 7.347, de 24 de julho de 1985; revoga dispositivos da Lei $n^{\circ}$ 8.884, de 11 de junho de 1994, e a Lei nㅇ 9.781, de 19 de janeiro de 1999; e dá outras providências. Diário Oficial da União, 01 de dez. de 2011. Disponível em: <http://www.planalto.gov.br/ccivil_03/_ato2011-2014/2011/Lei/L12529.htm>. Acesso em: 09 ago. 2014. 
CARRIL, Rodrigo Coutinho. Controle judicial sobre o cade e a análise econômica do direito.

Revista do IBRAC - Direito da Concorrência, Consumo e Comércio Internacional. São Paulo, V. 21/2012, Jan. 2012. Disponível em:

<http://www.revistadostribunais.com.br/maf/app/resultList/document?\&src=rl\&srguid=i0ad6007 a00000147c6961a12d087da19\&docguid=le8a8adf0e11f11e19781010000000000\&hitguid=le8a8a df0e11f11e19781010000000000\&spos=1\&epos=1\&td=1\&context=19\&startChunk=1\&endChunk= 1>. Acesso em: 11 ago. 2014.

CASTRO, Ramsés Maciel de. Controles dos aos de concentração de empresas realizados no Brasil e em países economicamente mais desenvolvidos: Justificativas para um regime normativo diferenciado no brasil. Disponível em:

<http://www.editoramagister.com/doutrina_25266222_CONTROLES_DOS_ATOS_DE_CONCENTRA CAO_DE_EMPRESAS_REALIZADOS_NO_BRASIL_E_EM_PAISES_ECONOMICAMENTE_MAIS_DESENV OLVIDOS_JUSTIFICATIVAS_PARA_UM_REGIME_NORMATIVO_DIFERENCIADO_NO_BRASIL.aspx>. Acesso em 04 ago. 2014.

DUTRA, Pedro. A concentração do poder econômico e a função preventiva do cade, Revista do IBRAC - Direito da Concorrência, Consumo e Comércio Internacional, São Paulo, v.4, jan. 1997. Disponível em:

<http://www.revistadostribunais.com.br/maf/app/resultList/document?\&src=rl\&srguid=i0ad6007 $900000147831358273 a 5 c b 08 f \&$ docguid=1030378c01cd011e1adf500008517971a\&hitguid=|03037 8c01cd011e1adf500008517971a\&spos=6\&epos $=6 \& \mathrm{td}=191 \&$ context=6\&startChunk=1\&endChunk =1\#>. Acesso 29 jul. 2014.

FORGIONI, Paula A. Os fundamentos do antitruste. 3. ed. São Paulo: Revista dos Tribunais, 2008

MONTEIRO, GABRIELA REIAS PAIVA. O novo sistema de análise prévia dos atos de concentração e a questão do gun-jumping: traçando parâmetros para as empresas. 2012. $63 \mathrm{f}$. Monografia (Graduação em Direito). - Fundação Getúlio Vargas, Escola de Direito FGV Direito Rio. Rio de Janeiro. Disponível em

<http://bibliotecadigital.fgv.br/dspace/bitstream/handle/10438/10792/Gabriela\%20Reis\%20Paiva \%20Monteiro.pdf?sequence=1>. Acesso em: 05 ago. 2014.

PAGOTTO, Leopoldo; MAGGI, Bruno Oliveira; GRECCO, Gabriel Noronha. A nova lei de defesa da concorrência - lei 12.529/2011. Revista do IBRAC - Direito da Concorrência, Consumo e Comércio Internacional. São Paulo, v. 7, jan. 2000. Disponível em <http://www.revistadostribunais.com.br/maf/app/latestupdates/document?\&src=rl\&srguid=i0ad $60079000001478877 \mathrm{~b} 73 \mathrm{ce} 8998 \mathrm{~d} 59 \&$ docguid $=\mid 4 \mathrm{bd025}$ c0789811e1940400008517971a\&hitguid $=1$ 4bd025c0789811e1940400008517971a\&spos=10\&epos=10\&td=123\&context=664\&startChunk=1 \&endChunk=1>. Acesso em 30 jul. 2014.

PUBLICAÇÕES DA ESCOLA DA AGU. Brasília: Escola da Advocacia Geral da União, 2009. Mensal. Ano IV - n 19. (Jul. 2012).

SALLES, Luiz Eduardo. Bomba-relógio ou marca-passo? O prazo de análise de concentrações na nova lei da concorrência. Revista do IBRAC - Direito da Concorrência, Consumo e Comércio Internacional, São Paulo, v. 21/2012, jan. 2012. Disponível em:

<http://www.revistadostribunais.com.br/maf/app/latestupdates/document?src=docnav\&ao=\&fro 
mrend=\&srguid=i0ad60079000001478846ea30be115feb\&epos $=21 \&$ spos $=21 \&$ page $=0 \&$ td $=108 \&$ sa vedSearch=\&searchFrom=\&context=33>Acesso em 30 jul. 2014. 